http://e-journal.stit-islamic-village.ac.id/index.php/JM2PI

\title{
Peningkatan Kemampuan Motorik Kasar Anak Usia Dini Melalui Permainan Lompat Tali Kelompok B1 di Tk Mutiara Tangerang
}

\author{
Nurul Arafah \\ Program Studi Pendidikan Islam Anak Usia Dini, STIT Islamic Village Tangerang \\ Email: nurularafah1997@gmail.com
}

Received: September, 2020.

Accepted: Oktober, 2020.

Published: November, 2020

\begin{abstract}
The puspose of this study is to increase gross motor skills of early childhood, through jumping rope games. This research is a class action research (PTK). Description of the data in this study using cycles such as planning, implementation cycles, observation and reflection. This research was conducted in Mutiara Kindergarten on January 28, 2020.

Based on the results of the study found after conducting this research, the data obtained starts from pre-cycle II, which is $46.8 \%$ pre cycle, in cycle 1 of $68 \%$ and the last cycle of $87 \%$ by obtaining a very good developing category. Improvements made during the research process have shown an increase in gross motor skills of early childhood.
\end{abstract}

Keywords: Jump Rope Games, Early Childhood Motor Rough

\section{ABSTRAK}

Tujuan penelitian ini ialah untuk peningkatan kemampuan motorik kasar anak usia dini, melalui permainan lompat tali. Penelitian ini merupakan penelitian tindakan kelas (PTK). Deskripsi data pada penelitian ini adalah menggunakan siklus seperti perencanaan, pelaksanaan sikelus, observasi dan refleksi.

Penelitian ini dilaksanakan di TK Mutiara pada tanggal 28 Januari 2020.

Berdasarkan hasil penelitian yang ditemukan setelah melakukan penelitian ini maka data yang diperoleh dimulai dari pra siklus - siklus II, yang mana pra siklus sebesar 46,8\%, pada siklus 1 sebesar 68\% dan siklus terakhir sebesar 87\% dengan memperoleh kategori berkembang sangat baik. Pembaikan pembaikan yang dilakukan selama proses penelitian telah menunjukan peningkatan motorik kasar anak usia dini.

Kata kunci: Permainan Lompat Tali, Motori 


\section{PENDAHULUAN}

Anak usia dini ialah anak yang berusia 0-8 tahun,"Anak usia dini tidak membedakan antara bermain, belajar dan bekerja, anak bermain secara alamiah. Mereka sangat menikmati permainan dan akan terus melakukanya dimanapun" (Zaenab, 2015 : 120)

Kegiatan bermain yang dilakukan dengan atau tanpa mempergunakan sebuah alat yang memberikan kesenangan dapat mengembangan imajinasi sang anak. Jika arti dari bermain dapat dipahami dan sangat kita kuasai, kemampuan itu akan berdampak sangat baik dan positif pada cara kita dalam mendampingi proses belajar anak usia dini. Dengan permainan tersebut, perkembangan motorik kasar anak akan dapat peningkatan dalam berkembang motorik, aktivitas motorik merupakan pengendalian gerakan tubuh melalui aktivitas yang terkoordinir antara susunan otak, otak dan urat saraf tulang belakang. Berdasarkan jenisnya aktivitas motorik bisa dibedakan menjadi dua, yaitu aktivitas motorik kasar dan motorik halus.

"Kemudian aktivitas motorik kasar adalah keterampilan gerak atau gerakan tubuh yang memakai otot-otot besar sebagai dasar utama gerakannya. Dan meliputi pola lokomotor (gerak yang menyebabkan perpindahan tempat)". (Rahyudi, 2014)

Melihat dari uraian di atas, peneliti memfokuskan kepada pengembangan motorik kasar dengan menggunakan permainan untuk mengembangkan motorik kasar dengan cara permainan lompat tali (main karet). Cara permainan tersebut anak dapat secara aktif menggunakan semua anggota tubuhnya secara maksimal dan diupayahkan dapat bermanfaat meningkatan dalam motorik kasar anak. 


\section{KAJIAN PUSTAKA}

\section{Pengertain Motorik}

"Motorik pada saat usia dini motorik sangatlah dibutuhkan, motorik dan gerak sering kali menjadi satu" (Kiram, 2019: 11).

Karena saling berkaitan motorik dapat menyebabkan suatu gerak. Macam-macam motorik adalah motorik kasar dan motorik halus jadi motorik kasar dan motorik halus berbeda pengertian.

"Motorik kasar adalah gerakan tubuh yang menggunakan otot-otot besar atau sebagian besar otot yang ada dalam tubuh yang dipengaruhi oleh kematangan diri” (Decaprio, 2013 : 18)

\section{Pengertain Motorik Kasar}

"Gerakan motorik kasar meliputi berbagai aktivitas otot-otot besar seperti otot tangan, otot kaki dan seluruh tubuh anak" (Sujiono, 2011: 13)

"Definisi dari motorik kasar selanjutnya menurut Diane (2015:315) adalah kemampuan fisik yang melibatkan bagian dari otot-otot yang besar"

Dari beberapa uraian di atas peneliti berpendapat motorik kasar adalah aktivitas yang menggunakan otot-otot besar pada tubuh dan bagian seluruh tubuh seseorang, jika tidak memiliki kemampuan motorik kasar yang baik dan tidak maksimal maka berdampak tertinggal dari orang yang memiliki motorik kasar yang maksimal contoh: lompat, lari, melempar dan mendorong.

\section{Pengertain Bermain}

Sehari-hari anak akan bermain dengan bermain anak, anak mendapatkan manfaat yang besar anak akan senang, gembira, dapat mengeluarkan energi dan sangat baik untuk perkembangan pada anak 
jadi dunia anak adalah bermain setiap bermain akan menghasilkan proses belajar pada anak.

Bermain sangat dibutuhkan oleh anak berikut adalah beberapa pengertian bermain menurut para ahli:

Menurut Herbert seorang ahli dari Inggris mengatakan bahwa bermain:

"bermain pada anak karena penumpukan tenaga pada anak maka perlu dilepaskan dalam bentuk kegiatan bermain, agar terjadi keseimbangan dalam diri anak" (Suherman, $2010: 57$ ).

Dari uraian diatas, bermain menyenangkan, menyalurkan tenaga yang berlebih dan muncul atas keinginan pribadi anak usia dini fleksibel, keseimbangan tubuh anak, melepaskan penumpukan energi anak, lebih menekan proses dari pada hasil, dan anak lebih bebas memilih yang anak sukai.

\section{Pengertain Permainan Tradisional}

"Adapun yang dimaksud dengan "tradisional" menurut kamus besar bahasa indonesia berasal dari kata dasar "tradisi" yang artinya antara lain “adat kebiasaan turun temurun yang masih dijalankan". (Ariani, 2015)

Sehubung dengan pengertian diatas, maka penulis dapat menyimpulkan bahwa permainan tradisional ialah segala sesuatu bentuk permainan yang sudah ada sejak jaman dahulu kala dan diwariskan secara turun temurun, dari generasi ke generasi hingga saat ini agar tidak punah.

\section{Pengertain Lompat Tali}

"Lompat adalah berarti menolak dengan satu kaki, Aktivitas melompat adalah membawa badan ke atas". (Siskariyanti, 2019 : 13)

Peralatan untuk membuat media permainan lompat tali (main karet) sangat mudah didapatkan karena berupa karet gelang. Karet gelang 
dapat ditemukan dengan mudah seperti di dapur rumah atau membeli di warung.

Permainan ini akan membuat anak-anak senang karena dapat membuat mereka bersosialisasi dengan teman-temannya, serta sangat banyak manfaat yang didapat, seperti mudah beradaptasi dengan lingkungan dan mempertahankan kemenangan agar mereka tidak mudah menyerah.

\section{METODE PENELITIAN}

"Istilah penelitian bukanlah hal yang baru bagi mahasiswa, peneliti, guru dan pemerhati pendidikan”. (Fitrah, $2017: 26)$

Dalam penelitian ini penulis akan melakukan penelitian tindakan kelas (PTK) dengan menggunakan metode bermain dalam kelas.

Penelitian tindakan kelas (PTK) merupakan suatu pengamatan terhadap kegiatan belajar berupa sebuah tindakan yang sengaja dimunculkan dan terjadi dalam sebuah kelas secara bersama dengan peresta didik di TK Mutiara.

Dengan tujuan tindakan penelitian kelas agar peserta didik bisa belajar secara maksimal dan guru dapat memberikan pelatihan motorik kasar pada pembelajaran di kelas dan untuk terjadinya suatu perubahan yang lebih baik dan dapat memecahkan permasalahan yang terjadi disuatu kelas.

\section{HASIL PENELITIAN}

\section{Deskripsi Tahap Studi Awal}

Data yang didapatkan dari hasil observasi kelompok B1 TK Mutiara Tangerang, dengan didampingi oleh guru kelas sambil berdiskusi, 
ditemukan bahwa masih terdapat beberapa anak yang dalam keaktifan dan kelincahan gerak belum dapat berleluasa. Peneliti melakukan observasi terhadap peserta didik di TK Mutiara kelompok B1 untuk menentukan seberapa rendah tingkat keaktifan gerak peserta didik. Observasi dilakukan pada hari Selasa, 28 januari 2020 dengan pokok pembahasan tema "lingkungan ku" dan sub tema "keluargaku".

Proses pembelajaran dari pembukaan sampai istirahat di Kelompok B1 TK Mutiara Tangerang ialah sebagai berikut:

a. Pembukaan:

1) Penerapan SOP Pembukaan "Berbaris"

2) Sport "lompat tali"

3) Berdoa

4) Berdiskusi tentang lingkunganku

5) Berdiskusi tentang keluargaku

b. Inti

1) Menceritakan anggota keluarga

2) Menggambar anggota keluarga

3) Mewarnai gambar anggota keluarga

4) Menggunting gambar anggota keluarga

5) Menghitung berapa jumlah anggota masing-masing keluarga

c. Istirahat 
Peningkatan Kemampuan Motorik Kasar Anak Usia Dini Melalui Permainan Lompat Tali Kelompok B1 DI TK Mutiara Tangerang

1) Cuci Tangan

2) Makan

3) Bermain

Dapat diperoleh data nilai tahap awal ialah terdapat berikut:

Tabel 4.1 :

Hasil Observasi Tahap Studi Awal

\begin{tabular}{|l|l|c|c|}
\hline No & Nama & $\begin{array}{l}\text { Hasil } \\
\text { Observasi } \\
\text { pra siklus }\end{array}$ & $\begin{array}{l}\text { Kriteria } \\
\text { Penilaian }\end{array}$ \\
\hline 1 & AFH & 5 & BB \\
\hline 2 & AG & 8 & MB \\
\hline 3 & AFN & 5 & BB \\
\hline 4 & AQ & 9 & MB \\
\hline 5 & AR & 11 & MB \\
\hline 6 & WN & 14 & BSH \\
\hline 7 & AK & 5 & BB \\
\hline 8 & FJ & 18 & BSB \\
\hline 9 & GS & 5 & BB \\
\hline 10 & MKS & & \\
\hline
\end{tabular}

JM2PI: Jurnal Mediakarya Mahasiswa Pendidikan Islam

Vol. 01, Nomor 02, November 2020 


\begin{tabular}{|l|l|c|c|}
\hline 11 & MR & 17 & BSB \\
\hline 12 & NB & 12 & BSH \\
\hline 13 & OM & 5 & BB \\
\hline 14 & ARA & 17 & BSB \\
\hline 15 & RVN & 6 & MB \\
\hline 16 & AY & 5 & BB \\
\hline Jumlah nilai & 150 & \\
\hline \multicolumn{2}{|l|}{ Rata-rata nilai } & $46,8 \%$ & MB \\
\hline
\end{tabular}

Dari data yang diperoleh di atas adalah $46,8 \%$, dari semua data jumlah seluruh peserta didik 6 BB (belum berkembang), 5 peserta didik dalam kategori MB (mulai berkembang), 2 peserta didik BSH (berkembang sesuai harapan) dan 3 peserta didik kategori BSB (berkembang sangat baik). Dan dari data di atas telah dapat secara keseluruhan data para peserta didik di TK Mutiara kelompok B1 dalam kategori tahap pra siklus.

Tabel 4.2 :

\section{Pra Siklus}

\begin{tabular}{|l|l|r|l|}
\hline No & Kategori & Pra siklus & Persentasi \\
& & $(\mathrm{F})$ & pra siklus \\
\hline
\end{tabular}




\begin{tabular}{|l|l|l|l|}
\hline & & & $(\%)$ \\
\hline 1. & BSB & 3 & $19 \%$ \\
\hline 2. & BSH & 2 & $12 \%$ \\
\hline 3. & MB & 5 & $31 \%$ \\
\hline 4. & BB & 6 & $37 \%$ \\
\hline
\end{tabular}

Nilai tersebut dapat disimpulkan bahwa masih banyak peserta didik yang belum berkembang secara maksimal pada kemampuan motorik kasar dan untuk karena menghadapi permasalahan penelti berusaha agar kemampuan motorik kasar dapat maksimal maka peneliti mencoba menerapkan belajar sambil bermain dengan permainan lompat tali di TK Mutiara kelompok B1.

Pembelajaran lompat tali sambil bermain dipilih karena guru dapat memaksimalkan perkembangan motorik kasar peserta didik dengan menggunakan alat dan bahan sederhana tetapi mampu mendapatkan hasil manfaat yang maksimal bagi pembelajaran di TK Mutiara.

\section{Deskripsi Tahap Siklus 1}

\section{a. Perencanaan}

Saat melakukan penelitian tindakan kelas siklus 1, peneliti sudah menyusun perencanaan pembelajaran yang akan dilaksanakan 
didalam kelas yang sudah didiskusikan dengan wali kelas TK Mutiara kelompok B1. Berikut adalah perencanaan siklus 1:

1). Menambahkan Sport "lompat tali" untuk ditambahkan pada (RPPH)

2). Mempersiapkan lembar observasi

3). Mempersiapkan alat permainan tradisional "lompat tali"

b. Pelaksanaan siklus 1

Pada saat peneliti melakukan pra siklus dan mendapatkan hasil yang diperoleh pada kemampuan motorik di TK Mutiara belum maksimal maka peneliti melanjutkan kepada tahap siklus 1 yang dilaksanakan pada tanggal 4 febuari 2020 peneliti melakukan pertemuan kembali dan peneliti melakukan observasi kembali pada tahap ini.

Anak didampingi dan dipimpin oleh guru untuk berbaris dan bernyanyi kemudian anak peserta didik melanjutkan untuk sport "lompat tali" yang di pimpin oleh guru dan peneliti melakukan observasi.

Pada saat pelaksanaan anak peserta didik mulai memperhatikan guru dan peserta didik satu persatu dipanggil namanya untuk melompati tali dan anak peserta didik sangat antusias senang melakukan belajar sambil bermain sport "lompat tali". 
c. Observasi

Proses observasi pada permainan lompat tali tahap siklus 1 masih mendapatkan kendala masih terdapat beberapa anak yang belum bisa bermain lompat tali, tetapi peserta didik sangat antusias saat belajar sambil bermain permainan. Pada saat peserta didik bermain permainan dengan teman-teman sekelasnya anak sangat gembira dan tersenyum tetapi ada beberapa anak yang tidak begitu semangat karena tidak bisa tetapi guru dan saya sebagai peneliti memberikan motivasi agar anak tidak pantang menyerah.

Kemudian anak peserta didik semua bersemangat dan satu persatu nama peserta didik dipanggil oleh peneliti dan anak selalu berusaha agar bisa melompati tali tersebut dan karena seiring berjalannya waktu peserta didik terbiasa untuk bisa melompati tali dan peserta didik paham cara bermain permainan tradisional lompat tali. Mulai dari melompat ubin, dengkul, ipis dan pinggang.

Indikator pada saat peneliti menteliti yaitu peserta didik agar mampu melakukan gerakan lompat, peserta didik mampu untuk berlari, peserta didik mampu memegang erat karet tali dan peserta didik mampu melompati karet tali dengan ketinggian tertentu. Oleh karena itu pada siklus 1 ini terlihat peserta didik telah berusaha dan terlihat sudah mampu dalam permainan lompat tali dan berdampak pada peningkatan dari pra siklus sampai pada tahap siklus 1 .

Hasil pada siklus 1 yang sebelumnya anak tidak semangat untuk bermain permainan lompat tali tetapi saat ini peserta didik bersemangat, begitu juga mengalami keraguan untuk berlari tetapi 
anak sudah tidak ragu lagi untuk berlari dan melompati tali tetapi saat ini anak sudah mampu melompati tali tersebut.

Pada saat tindakan siklus 1 mendapatkan hasil observasi yang menunjukan kemajuan pada Perkembangan kemampuan motorik kasar peserta didik di TK Mutiara kelompok B1 mengalami peningkatan setelah kegiatan pra siklus selama satu minggu anak bermain sambil berlatih lompat tali.

Tabel 4.3:

Siklus 1

\begin{tabular}{|c|c|c|c|}
\hline $\mathrm{No}$ & Nama & $\begin{array}{l}\text { Hasil } \\
\text { Observasi } \\
\text { siklus } 1\end{array}$ & $\begin{array}{l}\text { Kriteria } \\
\text { Penilaian }\end{array}$ \\
\hline 1 & $\mathrm{AFH}$ & 8 & $\mathrm{MB}$ \\
\hline 2 & $\mathrm{AG}$ & 13 & $\mathrm{BHS}$ \\
\hline 3 & $\mathrm{AFN}$ & 8 & MB \\
\hline 4 & $\mathrm{AQ}$ & 14 & $\mathrm{BHS}$ \\
\hline 5 & AR & 16 & BSB \\
\hline 6 & WN & 17 & BSB \\
\hline 7 & $\mathrm{AK}$ & 10 & $\mathrm{MB}$ \\
\hline 8 & FJ & 20 & $\mathrm{BSH}$ \\
\hline 9 & GS & 13 & $\mathrm{MB}$ \\
\hline
\end{tabular}


Peningkatan Kemampuan Motorik Kasar Anak Usia Dini Melalui Permainan Lompat Tali Kelompok B1 DI TK Mutiara Tangerang

\begin{tabular}{|l|l|c|c|}
\hline 10 & MKS & 11 & MB \\
\hline 11 & MR & 19 & BSH \\
\hline 12 & NB & 17 & BSH \\
\hline 13 & OM & 10 & MB \\
\hline 14 & ARA & 19 & BSB \\
\hline 15 & RVN & 12 & BSH \\
\hline 16 & AY & 11 & MB \\
\hline Jumlah nilai & 218 & \\
\hline \multicolumn{2}{|l|}{ Rata-rata nilai } & $68 \%$ & BSH \\
\hline
\end{tabular}

Data yang diperoleh di atas adalah $68 \%$, dari seluruh peserta didik, yaitu 0 peserta didik BB (belum berkembang), 7 peserta didik dalam kategori MB (mulai berkembang), 6 peserta didik dalam kategori BSH (berkembang sesuai harapan) dan 3 peserta didik dalam kategori BSB (berkembang sangat baik). Dari data di atas diperoleh data secara keseluruhan peserta didik di TK Mutiara kelompok B1 dalam kategori tahap siklus 1 .

\section{Tabel 4.4:}

Siklus 1

\begin{tabular}{|l|l|l|l|}
\hline No & Kategori & $\begin{array}{l}\text { Tahap Siklus } \\
1\end{array}$ & $\begin{array}{l}\text { Persentasi } \\
\text { Siklus 1 }\end{array}$ \\
\hline
\end{tabular}




\begin{tabular}{|l|l|l|l|}
\hline & & \multicolumn{1}{|c|}{$(\mathrm{F})$} & $(\%)$ \\
\hline 1. & BSB & 3 & $19 \%$ \\
\hline 2. & BSH & 6 & $37 \%$ \\
\hline 3. & MB & 7 & $44 \%$ \\
\hline 4. & BB & 0 & $0 \%$ \\
\hline
\end{tabular}

Nilai tersebut dapat disimpulkan bahwa terdapat hasil peningkatan pada anak peserta tetapi peneliti masih menemukan hasil yang belum mencapai target $80 \%$ untuk mendapatkan kategori berkembang sangat baik dari keseluruhan anak peserta didik dan hasil belum maksimal pada kemampuan motorik kasar dan untuk menghadapi permasalahan penelti berusaha agar kemampuan motorik kasar dapat maksimal maka peneliti mencoba menerapkan belajar sambil bermain dengan permainan lompat tali di TK Mutiara kelompok B1 melanjutkan siklus selanjutnya.

Pembelajaran lompat tali sambil bermain dipilih karena guru dapat memaksimalkan perkembangan motorik kasar peserta didik dengan menggunakan alat dan bahan sederhana tetapi mampu mendapatkan hasil manfaat yang maksimal bagi pembelajaran di TK Mutiara.

\section{d. Refleksi}

Berdasarkan hasil pada siklus 1, secara keseluruhan peserta didik masih terdapat hasil yang belum maksimal. Dari hasil observasi 
peneliti pada tahap siklus 1 belum mencapai target $80 \%$ dari keseluruhan peserta didik sehingga peneliti mengambil langkah tindakan melanjutkan siklus berikutnya yaitu siklus ke II.

Dari hasil siklus 1 yang belum mencapai $80 \%$ maka belum mencapai hasil yang maksimal. Perlu dilakukan perbaikan pada siklus II untuk mendapatkan hasil yang optimal bagi keseluruhan peserta didik. Peneliti akan menambahkan beberapa langkah untuk perbaikan guna mencapai hasil yang maksimal pada siklus II. Berikut adalah langkah-langkah yang peneliti ambil dalam perbaikan pada siklus selanjutnya:

1) Peneliti memberikan masukan kepada guru agar guru lebih fokus dalam memberikan stimulasi kepada peserta didik mengenai perkembangan motorik kasar yang dimiliki anak, seperti memberikan arahan yang lebih jelas kepada anak dalam melakukan permainan lompat tali.

2).Peneliti memberikan masukan kepada guru agar guru dapat membuat peserta didik lebih bersemangat dalam permainan lompat tali guna meningkatkan motorik kasar peserta didik, melalui cara memberikan reward berupa biskuit kepada peserta didik yang berhasil mencapai nilai sesuai dengan penilaian indikator. 


\section{Deskripsi Tahap Siklus II}

a. Perencanaan

Peneliti sudah didiskusikan dengan wali kelas kelompok B1 TK Mutiara Tangerang yang akan dilaksanakan didalam kelas. Berikut adalah perencanaan siklus II:

1). Menambahkan Sport "lompat tali" untuk ditambahkan pada RPPH

2). Mempersiapkan lembar observasi

3). Mempersiapkan alat permainan tradisional "lompat tali"

b. Pelaksanaan siklus II

Pelaksanaan siklus 2 dengan guru kelas TK Mutiara kelompok B1. Tugas guru adalah mengarahkan peserta didik dalam permainan lompat tali dan tugas peneliti yakni melakukan RPPH yang telah didiskusikan diawal dan peneliti memanggil nama anak satu persatu untuk penilaian sambil mendokumentasikan.

Pertemuan siklus II diadakan pada Selasa tanggal 11 Febuari 2020 dengan tema "Air" dan sub tema "Guna Air Untuk Mandi". Pada saat silkus II seperti biasa guru memberikan pengarahan kepada peserta didik tentang permainan lompat tali dan menjelaskan tentang reward yang akan diberikan kepada peserta didik yang telah berhasil secara baik dan benar saat pelaksanaan kegiatan permainan lompat tali siklus II.

c.Observasi 
Pada tahap observasi siklus II peserta didik sangat memahami alur kegiatan permainan lompat tali dikarenakan sudah terbiasa dengan permainan tradisional ini. Seluruh peserta didik sangat baik melakukan permainan lompat tali. Pada tahap siklus II peserta didik terlihat sangat antusias, apalagi ketika guru memberikan motivasi berupa reward yang akan diberikan jika mereka berhasil.

Tabel 4.5:

Hasil Observasi Tahap tindakan siklus II

\begin{tabular}{|l|l|c|c|}
\hline No & Nama & $\begin{array}{l}\text { Hasil } \\
\text { Observasi } \\
\text { siklus 1 }\end{array}$ & $\begin{array}{l}\text { Kriteria } \\
\text { Penilaian }\end{array}$ \\
\hline 1 & AFH & 15 & BSH \\
\hline 2 & AG & 18 & BSB \\
\hline 3 & AFN & 14 & BSH \\
\hline 4 & AQ & 18 & BSB \\
\hline 5 & AR & 19 & BSB \\
\hline 6 & WN & 19 & BSB \\
\hline 7 & AK & 18 & BSB \\
\hline 8 & FJ & 18 & BSB \\
\hline 9 & GS & 16 & BSB \\
\hline 10 & MKS & & \\
\hline
\end{tabular}




\begin{tabular}{|l|l|c|c|}
\hline 11 & MR & 20 & BSB \\
\hline 12 & NB & 19 & BSB \\
\hline 13 & OM & 17 & BSB \\
\hline 14 & ARA & 20 & BSB \\
\hline 15 & RVN & 14 & BSH \\
\hline 16 & AY & 14 & BSH \\
\hline Jumlah nilai & 279 & \\
\hline \multicolumn{2}{|l|}{ Rata-rata nilai } & $87 \%$ & BSB \\
\hline
\end{tabular}

Dari data penilaian siklus II nilai rata-rata mencapai $87 \%$ dalam kategori Berkembang Sangat Baik (BSB). Hal ini memperlihatkan peningkatan yang terjadi pada perkembangan motorik kasar anak usia dini di TK Mutiara kelompok B 1 yang berjumlah 16 peserta didik. Tabel dibawah ini:

Tabel 4.6:

Rangkuman Peningkatan

\begin{tabular}{|l|l|l|l|}
\hline Persentase & $\begin{array}{l}\text { Jumlah Peserta } \\
\text { didik }\end{array}$ & $\begin{array}{l}\text { Persentase } \\
\text { Jumlah Anak }\end{array}$ & Keterangan \\
\hline
\end{tabular}


Peningkatan Kemampuan Motorik Kasar Anak Usia Dini Melalui Permainan Lompat Tali Kelompok B1 DI TK Mutiara Tangerang

\begin{tabular}{|l|l|l|l|}
\hline $80 \%-100 \%$ & 12 & $75 \%$ & BSB \\
\hline $60 \%-79 \%$ & 4 & $25 \%$ & BSH \\
\hline $30 \%-59 \%$ & 0 & 0 & MB \\
\hline $0 \%-29 \%$ & 0 & 0 & BB \\
\hline
\end{tabular}

\section{d.Refleksi}

Pada kegiatan refleksi siklus II secara keseluruhan peneliti dan guru menyatakan berjalan dengan baik dan lancar untuk perkembangan. Keberhasilan tersebut dapat terlihat dari tabel dibawah ini:

Tabel 4.7

\section{Rangkuman peningkatan}

\begin{tabular}{|c|c|c|c|}
\hline \multirow{2}{*}{ Keterangan } & \multicolumn{3}{|c|}{ Jumlah Anak } \\
\cline { 2 - 4 } & Pra tindakan & Siklus 1 & Siklus II \\
\hline BSB & 3 & 3 & 12 \\
\hline BSH & 2 & 6 & 4 \\
\hline MB & 5 & 7 & 0 \\
\hline BB & 6 & 0 & \\
\hline
\end{tabular}


Tabel 4.8

Peningkatan Motorik Kasar Anak Dari Pra Siklus-Siklus II

\begin{tabular}{|c|c|c|c|c|c|}
\hline $\mathrm{No}$ & $\begin{array}{l}\text { Kode } \\
\text { Anak }\end{array}$ & $\begin{array}{c}\text { Pra } \\
\text { tindakan }\end{array}$ & Siklus 1 & $\begin{array}{c}\text { Siklus } \\
\text { II }\end{array}$ & Keterangan \\
\hline 1 & $\mathrm{AFH}$ & $25 \%$ & $40 \%$ & $75 \%$ & Meningkat \\
\hline 2 & $\overline{A G}$ & $40 \%$ & $65 \%$ & $90 \%$ & Meningkat \\
\hline 3 & $\mathrm{AFN}$ & $25 \%$ & $40 \%$ & $70 \%$ & Meningkat \\
\hline 4 & $\mathrm{AQ}$ & $45 \%$ & $70 \%$ & $90 \%$ & Meningkat \\
\hline 5 & AR & $55 \%$ & $80 \%$ & $95 \%$ & Meningkat \\
\hline 6 & $\mathrm{WN}$ & $70 \%$ & $85 \%$ & $95 \%$ & Meningkat \\
\hline 7 & $\mathrm{AK}$ & $25 \%$ & $50 \%$ & $90 \%$ & Meningkat \\
\hline 8 & $\mathrm{FJ}$ & $90 \%$ & $100 \%$ & $100 \%$ & Meningkat \\
\hline 9 & GS & $40 \%$ & $65 \%$ & $90 \%$ & Meningkat \\
\hline 10 & MKS & $25 \%$ & $55 \%$ & $80 \%$ & Meningkat \\
\hline 11 & MR & $85 \%$ & $95 \%$ & $100 \%$ & Meningkat \\
\hline 12 & NB & $60 \%$ & $85 \%$ & $95 \%$ & Meningkat \\
\hline 13 & $\mathrm{OM}$ & $25 \%$ & $50 \%$ & $85 \%$ & Meningkat \\
\hline 14 & ARA & $85 \%$ & $95 \%$ & $100 \%$ & Meningkat \\
\hline 15 & RVN & $30 \%$ & $60 \%$ & $70 \%$ & Meningkat \\
\hline
\end{tabular}


Peningkatan Kemampuan Motorik Kasar Anak Usia Dini Melalui Permainan Lompat Tali

Kelompok B1 DI TK Mutiara Tangerang

\begin{tabular}{|c|c|c|c|c|c|}
\hline 16 & AY & $25 \%$ & $55 \%$ & $70 \%$ & Meningkat \\
\hline $\begin{array}{c}\text { Jumlah } \\
\text { nilai }\end{array}$ & 150 & 218 & 279 & Meningkat \\
\hline $\begin{array}{c}\text { Nilai } \\
\text { rata- } \\
\text { rata }\end{array}$ & $46,8 \%$ & $68 \%$ & $87 \%$ & Meningkat \\
\hline
\end{tabular}

Berdasarkan tabel di atas dapat disimpulkan ada peningkatan dalam setiap tindakan yang terjadi dari pra siklus menjadi 46,8\% dan ketika siklus 1 menjadi 68\% begitu juga dengan siklus 1 dari 68\% saat siklus II menjadi 87\%, untuk lebih jelas dapat terlihat pada tabel di bawah ini:

Tabel 4.9: Peningkatan Setiap Siklus

\begin{tabular}{|c|c|c|l|}
\hline Keterangan & Pra siklus & Siklus 1 & Siklus II \\
\hline Rata-rata & $46,8 \%$ & $68 \%$ & $87 \%$ \\
\hline
\end{tabular}

\section{SIMPULAN}

Dari analisis penulis menyimpulkan bahwa menunjukan adanya hubungan antara aktivitas bermain lompat tali dengan perkembangan motorik kasar dan terdapat peningkatan pada pra siklus $46,8 \%$, siklus I terdapat peningkatan $68 \%$ dan pada siklus II mencapai peningkatan $87 \%$. 


\section{REFERENSI}

Ariani. (2015). Jurnal Sejarah dan Budaya. Sejarah dan Budaya Indonesia.

Decaprio, R. (2013). aplikasi teori pembelajaran motorik di sekolah. jogjakarta: diva press..

Fitrah, M. (2017). metodelogi penelitian. sukabumi: CV jejak.

Kiram, Y. (2019). Belajar Keterampilan Motorik. Jakarta: Prenadamedia Group.

Rahyudi, H. (2014). Teori-Teori Belajar dan Aplikasi Pembelajaran Motorik. Majalengka: Nusa Media.

Siskariyanti. (2019 : 13). Pengembangan pergerakan permainan untuk atletik sekolah dasar kelas $V$. ponorogo: Uwais Inspirasi Indonesia.

Sugiyono. (2011 : 2). metode penelitian. Bandung: alfabeta.

Suherman. (2010). Buku saku perkembangan anak. Jakarta: EGC.

Zaenab, S. (2015). profesionalisme guru PAUD menuju NTB bersaing. yogyakarta: CV budi utama. 